\title{
Identifikasi Kesalahan Teknik Smash Bola Voli Klub Meteor
}

\author{
Oviesta Tasha Retyananda ${ }^{1}$, Eka Supriatna², Isti Dwi Puspita Wati ${ }^{3}$ \\ Pendidikan Kepelatihan Olahraga, Universitas Tanjungpura, Indonesia.
}

\section{Informasi Artikel}

Diterima 2021-04-14

Direvisi 2021- 05-28

Dipublikasikan 2021-06-23

\section{Keyword:}

Identifikasi

Teknik

Smash

\begin{abstract}
The research motivated by the problem of lack of correction in the volleyball smash technique. This study aims to identify the errors of the Pontianak meteor club volleyball player smash technique. Thi research was a descriptive percentage. The method used was a survey with an observation sheets, field observations, and documentation. The sample in this study consisted of 11 athletes who have the criteria: (1) athlete were present at the time of data collection, (2) athlete who has a specialist as a speaker. The data analysis technique used a descriptive analysis which an stated in the form of a percentage. The results showed that there was an error volleyball smash technique in: (1) the initial stage was $25.39 \%$, (2) the repulsion / jump stage was $25.37 \%$, (3) the hitting stage was $25.42 \%$ and, (4) when landing is $23.82 \%$. So it can be concluded that the landing stage has the largest percentage of errors.
\end{abstract}

(c) 2020 The Authors. Published by Universitas Negeri Padang.

This is an open access article under the CC BY-NC-SA license (https://creativecommons.org/licenses/by-nc-sa/4.0/

\section{Penulis Korespondensi:}

2Eka Supriatna

Pendidikan Kepelatihan Olahraga, Universitas Tanjungpura

eka.supriatna@fkip.untan.ac.id

\section{PENDAHULUAN}

Permainan bola voli termasuk dalam permainan yang modern saat ini, tidak hanya sebagai olahraga rekreasi, akan tetapi telah berkembang menjadi olahraga pendidikan dan olahraga yang dipertandingkan. Permainan bola voli juga merupakan salah satu cabang olahraga yang digemari masyarakat luas Idris (Moh.Latar, 2015). Hal ini disebabkan karena permainan bola voli tidak memerlukan biaya yang besar karena alat dan perlengkapannya relatif murah dan mudah didapat. Kepopulerannya dapat terlihat pada antusiasme masyarakat dalam berbagi usia, mulai dari usia anak anak, remaja, dan dewasa dalam menyaksikan setiap kejuaraan, baik kejuaraan antar sekolah, POPDA, POPNAS, O2SN hingga proliga (Muttaqin dkk, 2016). Selain itu, bolavoli juga merupakan olahraga yang berkembang sesuai dengan kemajuan zaman (Rohendi \& Suwandar, 2017: 14). Pada era modern ini seharusnya pembinaan di berbagai klub bola voli sudah dilakukan secara bertahap mulai dari pemula hingga senior (Ismoko \& Sukoco, 2013). Spesialisasi dikembangkan dalam olahraga bola voli yang bertujuan untuk mencapai efektivitas serta efisiensi dalam permainan, sehingga dapat menghasilkan prestasi yang optimal.

Bola voli dikatakan sebagai permainan beregu yang dimainkan oleh dua tim dimana di setiap tim terdiri dari enam orang pemain untuk berlomba mencapai angka 25 terlebih dahulu (Hidayat dkk, 2018). Permainan bolavoli dapat dimainkan dalam segala bentuk jenis lapangan. Baik rungan tertutup, maupun ruangan terbuka. Cara bermain dalam permainan bolavoli menggunakan sistem rally poin (Moh.Latar, 2015). Dimana kedua regu berhak mendapatkan score setiap regu tersebut memenangkan suatu kejadian dalam permainan. Permainan bola voli merupakan permainan yang dimainkan secara berkelompok, artinya setiap individu harus mampu bekerjasama dengan baik, dan bertanggung jawab dalam tim (Muhamad Muhyi Faruq, 2009). 
Teknik dalam permainan bolavoli meliputi service, passing, block, dan smash Menurut Iskandar dan (Yulianingsih, 2015). Teknik adalah suatu cara yang digunakan oleh seseorang untuk menyelesaikan suatu tugas gerakan olahraga secara efekif dan efisien (Syafruddin, 2011: 125-126). Penguasaan teknik dalam bolavoli merupakan unsur yang dapat menentukan kemenangan tim dalam suatu pertadingan (Munasifah, 2009: 26). Penguasan terhadap keterampilan teknik dasar adalah hal yang sangat penting (Rajidin, 2016). Selain itu, teknik dasar harus dilatihkan secara sistematis, berulang ulang, dan berkelanjutan guna mencapai hasil yang optimal.

Bola voli adalah olahraga dinamis dan kompleks yang ditekankan pada bagian teknis serta taktis (Forthomme, et al. 2005). Gerakan-gerakkan yang diterapkan dalam bola voli pada dasarnya merupakan gerakan keterampilan. Pelaksanaan geraknya menggunakan koordinasi antara bagianbagian tubuh dan keseluruhan tubuh. Rangkaian antara seluruh bagian gerakkan berisi tentang kemahiran memadukan beberapa tahap gerak menjadi suatu gerakan yang koordinatif. Gerakan teknik dalam bola voli didominasi oleh gerakan lengan dan tangan, Sebagaimana salah satu jenis gerak keterampilan bola voli berupa smash, untuk dapat melakukan smash dengan baik, seorang atlet harus memiliki koordinasi dan akurasi (Lenberg, 2006). Koordinasi mata-tangan yang kurang akan menyebabkan pukulan tidak optimal, maka dari itu diperlukan koordinasi mata-tangan yang baik agar dapat mendukungan keberhasilan smash bola voli. Komponen biomotor sangat menentukan keberhasilan dalam suatu gerak selain teknik dan taktis khusunya yang berkaitan dengan teknik smash.

Smash dan spike adalah dua hal yang sama berupa pukulan keras dari atas ke bawah yang yang menuntut koordinasi dari berbagai macam sub-gerak. Smash merupakan salah satu teknik yang paling banyak menyumbangkan angka dalam permainan bola voli, karena smash merupakan pukulan yang dilakukan menggunakan teknik tertentu dengan tujuan agar bola tersebut dapat memasuki lapangan lawan main sehingga dapat mematahkan sistem pertahanan lawan untuk memperoleh nilai atau angka. Serangan merupakan tindakan terencana yang dilakukan untuk menghancurkan pertahanan lawan dalam mencapai kemenangan (Edi Irwanto,2016). Ahli lain berpendapat bahwa smash adalah suatu teknik serangan yang digunakan dalam permainan bola voli guna memperoleh nilai atau angka (Nugroho, 2018). Teknik ini yang memepengaruhi kemenangan dalam tim. Smash atau spike dapat ditegorikan sebagai keahlian yang digunakan untuk memainkan bola di atas net (Rohendi dan Suwandar, 2017: 81). Berhasil atau tidaknya serangan, tergantung pada pemberian bola dari tosser kepada penyerang (Beutelstahl, 2007: 71). Terdapat beberapa strategi serangan bolavoli, diantaranya posisi 4,3,2 dan 1,6,5 belakang garis serang (Mutohir, 2013: 116-117). Smasher merupakan pemain terpenting dalam tim (Trajković, 2011). Beberapa tahun terakhir para ilmuwan olahraga telah mulai memusatkan studi mereka pada serangan dalam permainan bola voli yang didefinisikan sebagai "kunci" permainan (Widyanto \& Hidayat, 2019).

Tedapat 6 wilayah dalam serangan (posisi 1 hingga 6) yanng sesuai dengan aturan FIVB. Ketiga diantaranya yaitu posisi 1,6,5 yang disebut serangan baris kedua/baris belakang (Laporta dkk, 2015) dan ketiga lainnya yaitu posisi 2,3,4 yang disebut serangan depan, posisi ini sering digunakan untuk menyerang. Teknik smash adalah teknik yang paling sulit dilakukan karena memiliki gerakan yang komplek sehingga teknik smash harus dilatihkan secara terperinci sejak awal (Pranopik, 2017). Efektivitas dalam smash dapat mempengaruhi kemampuan fisik serta penguasaan keterampilan menyerang (Suhairi dkk, 2019). Selama eksekusi smash, pemain melompat tinggi ke udara dan memukul bola pada titik tertinggi lompatan dalam upaya untuk mendorong bola dengan cepat ke arah sisi berlawanan (Seyfadin dkk, 2016).

Terdapat empat tahapan dalam gerakan smash yaitu, awalan, tolakan, perkenaan, dan mendarat. Dapat dilihat dari beberapa penelitian terdahulu seperti penelitian identifikasi gerak smash bola voli Yuso Sleman dalam empat tahapan termasuk dalam kategori "sedang" dengan persentase tahap awalan sebesar 36,36\%, tahap meloncat sebesar $25,76 \%$, tahap memukul sebesar 33,33\%, dan mendarat sebesar 4,55\% (Eko Santoso, 2019). Sedangkan penelitian tentang analisis smash bola voli pada Klub Gaveno Yogyakarta termasuk dalam kategori "cukup" dengan persentase pada tahap awalan sebesar $22,15 \%$, pada tahap pelaksanaan sebesar $21,90 \%$, dan pada tahap akhir sebesar 13,19\% (Alwi Kurnianto, 2012). Berdasarkan penelitian diatas menunjukkan bahwa, atlet kurang menguasai teknik smash bola voli dan tidak menyadari kesalahan kesalahan 
yang dilakukan, baik berupa gerakkan smash hingga perolehan hasil sehingga, dapat merugikan atlet dalam melakukan gerakan yang seharusnya lebih efektif dan efisien. Kemampuan smash yang baik merupakan kebutuhan wajib yang harus dimiliki oleh setiap spiker untuk mematikan lawan.

Kontribusi dari penelitian ini yaitu, peneliti perlu mengidentifikasi kesalahan dalam melakukan smash pada klub meteor Pontianak agar lebih komprehensif dengan cara menelaah suatu tindakan yang kurang tepat dalam proses gerak memukul bola secara kompleks berdasarkan pola gerak yang tepat dengan menggunakan beberapa tahapan berupa awalan, pelaksanaan, dan akhiran dalam satu rangkaian gerak sehingga, menghasilkan sebuah data yang akurat dan dapat digunakan untuk meminialisir kesalahan kesalahan yang dilakukan atlet dalam melakukan smash sekaligus menjadi perbaikkan pelatih dalam proses melatih agar kedepannya tidak terjadi kesalahan kesalahan yang sama. Untuk menganalisis sebuah teknik smash yang baik diperlukan suatu kajian analisis berupa biomekanika. Biomekanika digunakan untuk mempelajari gaya internal dan eksternal yang bekerja pada tubuh manusia serta efek yang dihasilkan oleh gaya tersebut (Blazevich, 2010).

\section{METODE}

Penelitian ini merupakan penelitian deskriptif persentase. Metode yang digunakan dalam penelitian ini berupa survei dengan meggunakan lembar observasi melalui pengamatan secara langsung dengan sampel sebanyak 11 orang dengan kriteria: (1) atlet hadir pada saat pengambilan data, (2) atlet yang memiliki spesialis sebagai spiker.

Teknik pengumpulan data yang digunakan dalam penelitian ini berupa pengamatan, yaitu atlet melakukan smash sebanyak 5 kali pukulan dengan bola yang dilontarkan oleh pengumpan, disertai dengan pengamatan dan penilaian yang dilakukan oleh tiga orang judge yang dianggap kompeten dalam bidang bola voli. Instrumen yang digunkan berupa lembar observasi berisikan pernyataan pernyataan yang sesuai dengan objek dari pengamatan. Serta teknik analisisi data menggunakan uji validitas, reliabilitas, T.score, serta persentase dengan mengelompokkan tingkatan tingkatan yang ada menggunakan Penilaian Acuan Norma (PAN) sebagai pembanding skor yang diperoleh dengan standar sesuai rata rata(Alfath \& Raharjo, 2019).

\section{HASIL DAN PEMBAHASAN}

\section{Hasil Penelitian}

Berikut data yang telah diperoleh dari penelitian menggunakan indikator penilaian teknik smash bola voli yang dinilai oleh tiga orang judge dapat dilihat pada Tabel 1.

Tabel 1. Hasil Data Penelitian

\begin{tabular}{|c|c|c|c|c|c|}
\hline No. & Awalan & Tolakan & Memukul & Mendarat & Total \\
\hline 1. & 57,9 & 57,8 & 56,3 & 54,5 & 226,8 \\
\hline 2. & 43,3 & 57,8 & 56,3 & 29,5 & 186,9 \\
\hline 3. & 57,9 & 32,9 & 56,3 & 54,5 & 201,6 \\
\hline 4. & 57,9 & 32,9 & 26,8 & 42 & 159,6 \\
\hline 5. & 43,3 & 57,8 & 46,4 & 54,5 & 202 \\
\hline 6. & 57,9 & 45,4 & 46,4 & 54,5 & 204,2 \\
\hline 7. & 57,9 & 45,4 & 46,4 & 42 & 191 \\
\hline 8. & 43,3 & 57,8 & 65,9 & 54,5 & 221,5 \\
\hline 9. & 57,9 & 57,8 & 46,4 & 33 & 195,1 \\
\hline 10. & 28,6 & 45,4 & 46,4 & 42 & 162,4 \\
\hline 11. & 43,3 & 57,8 & 56,3 & 54,5 & 211,9 \\
\hline Jumlah & 549,2 & 548,8 & 549,9 & 515,5 & 2.163 \\
\hline Mean & & & 196,63 & & \\
\hline SD & & & 221,51 & & \\
\hline Min & 28,6 & 32,9 & 26,8 & 29,5 & 159,6 \\
\hline Max & 57,9 & 57,8 & 56,3 & 54,5 & 226,8 \\
\hline
\end{tabular}


Perhitungan data statistik identifikasi kesalahan teknik smash bola voli menghasilkan rerata sebesar 196,63 dan standar deviasi sebesar 221,51. Adapun nilai terkecil 159,6 dan nilai terbesar 226,8. Berikut tampilan distribusi persentase penilaian teknik smash bola voli dapat dilihat pada Tabel 2.

Tabel 2. Norma Persentase Penilaian Teknik Smash Bola Voli

\begin{tabular}{clccc}
\hline No & \multicolumn{1}{c}{ Interval } & Kategori & Frekuensi & $\%$ \\
\hline 1 & $\geq 528,89$ & SangatBaik & 0 & $0,00 \%$ \\
2 & $528,89-307,38$ & Baik & 0 & $0,00 \%$ \\
3 & $307,38-196,63$ & Cukup & 6 & $54,55 \%$ \\
4 & $196,63-85,75$ & Kurang & 5 & $45,45 \%$ \\
5 & $\leq-135,63$ & Sangat Kurang & 0 & $0,00 \%$ \\
& & & 11 & $100 \%$ \\
\hline
\end{tabular}

Berdasarkan kriteria analisis pada tabel 2, menunjukkan bahwa identifikasi kesalahan teknik smash bola voli klub meteor Pontianak termasuk dalam kategori "cukup" dengan nilai rata rata atlet yaitu 196,63. Adapun pembagian dalam kategori "sangat baik" sebesar 0,00\% (0 atlet), kategori "baik" sebesar 0,00\% (0 atlet), kategori "cukup" sebesar 54,55\% (6 atlet), kategori "kurang" sebesar 45,45\% (5 atlet), dan kategori "sangat kurang" sebesar 0,00\% (0 atlet).

Identifikasi kesalahan teknik smash bola voli klub meteor Pontianak terbagi dalam 4 tahapan yaitu, awalan, tolakan/loncatan, memukul bola, dan mendarat. Berikut presentase kesalahan teknik smash bola voli klub meteor pontianak dapat dilihat pada Tabel 3.

Tabel 3. Kesalahan Teknik Smash Bola Voli

\begin{tabular}{lccc}
\hline & Faktor & Skor & $\%$ \\
\hline Awalan & 549,2 & $25,39 \%$ \\
Tolakan/loncatan & 548,8 & $25,37 \%$ \\
Memukul & 549,9 & $25,42 \%$ \\
Mendarat & 515,5 & $23,82 \%$ \\
& Jumlah & 2.163 & $100 \%$ \\
\hline
\end{tabular}

Beberapa rincian identifikasi kesalahan teknik smah bola voli klub meteor Pontianak mulai dari awalan, tolakan/loncatan, memukul bola, serta mendarat:

Pada tabel 4, menunjukkan bahwa identifikasi kesalahan teknik smash bola voli klub meteor Pontianak pada tahap awalan dominan terjadi ketika awalan melangkah pertama tidak pendek, yaitu sebanyak 6 atlet.

Tabel 4. Kesalahan Saat Awalan

\begin{tabular}{llcl}
\hline No & \multicolumn{1}{c}{ Indikator } & Ya & Tidak \\
\hline 1. & $\begin{array}{l}\text { Togok sedikit membungkuk condong ke } \\
\text { depan }\end{array}$ & 6 atlet & 5 atlet \\
2. & Badan menghadap ke arah datangnya bola & 10 atlet & 1 atlet \\
3. & $\begin{array}{l}\text { Posisi kepala rileks menyesuaikan arah } \\
\text { bola }\end{array}$ & 11 atlet & 0 atlet \\
4. & Lengan rileks di depan dada & 7 atlet & 4 atlet \\
5. & Posisi kaki rileks saat melangkah & 10 atlet & 1 atlet \\
6. & Langkah pertama pendek & 5 atlet & 6 atlet \\
\hline
\end{tabular}

Apabila ditampilkan dalam bentuk diagram, maka hasil identifikasi kesalahan teknik smash bola voli klub meteor Pontianak pada tahap awalan tampak pada gambar sebagai berikut: 


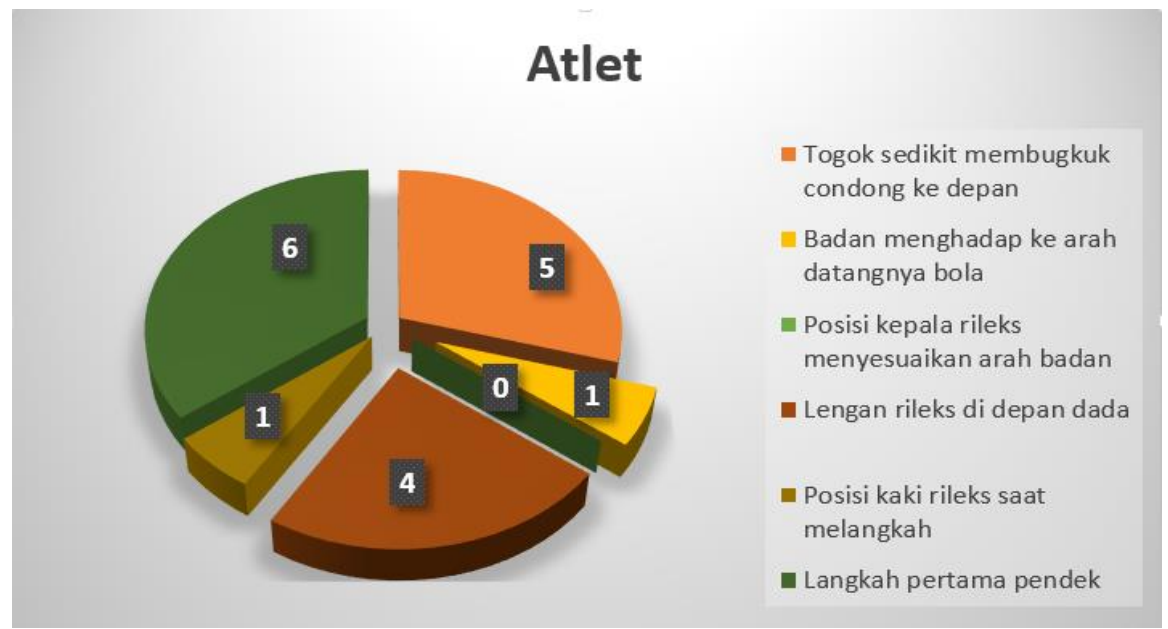

Gambar 1. Diagram Kesalahan Saat Awalan

Pada tabel 5, menunjukkan bahwa identifikasi kesalahan teknik smash bola voli klub meteor Pontianak pada tahap tolakan/loncatan dominan terjadi ketika atlet tidak menyerongkan pinggu sebesar 45 derajat, yaitu sebanyak 3 atlet.

Tabel 5. Kesalahan Saat Awalan

\begin{tabular}{|c|c|c|c|}
\hline No & Indikator & Ya & Tidak \\
\hline 1 & $\begin{array}{l}\text { Ketika akan melompat, tangan berada di } \\
\text { belakang badan }\end{array}$ & 11 atlet & 0 atlet \\
\hline 2 & Menekuk lutut menjelang lompatan & 9 atlet & 2 atlet \\
\hline 3 & $\begin{array}{l}\text { Posisi kaki rileks mengikuti bagian atas } \\
\text { badan }\end{array}$ & 9 atlet & 2 atlet \\
\hline 4 & Pinggul serong 45 derajat & 8 atlet & 3 atlet \\
\hline
\end{tabular}

Apabila ditampilkan dalam bentuk diagram, maka hasil identifikasi kesalahan teknik smash bola voli klub meteor Pontianak pada tahap tolakan/loncatan tampak pada gambar sebagai berikut:

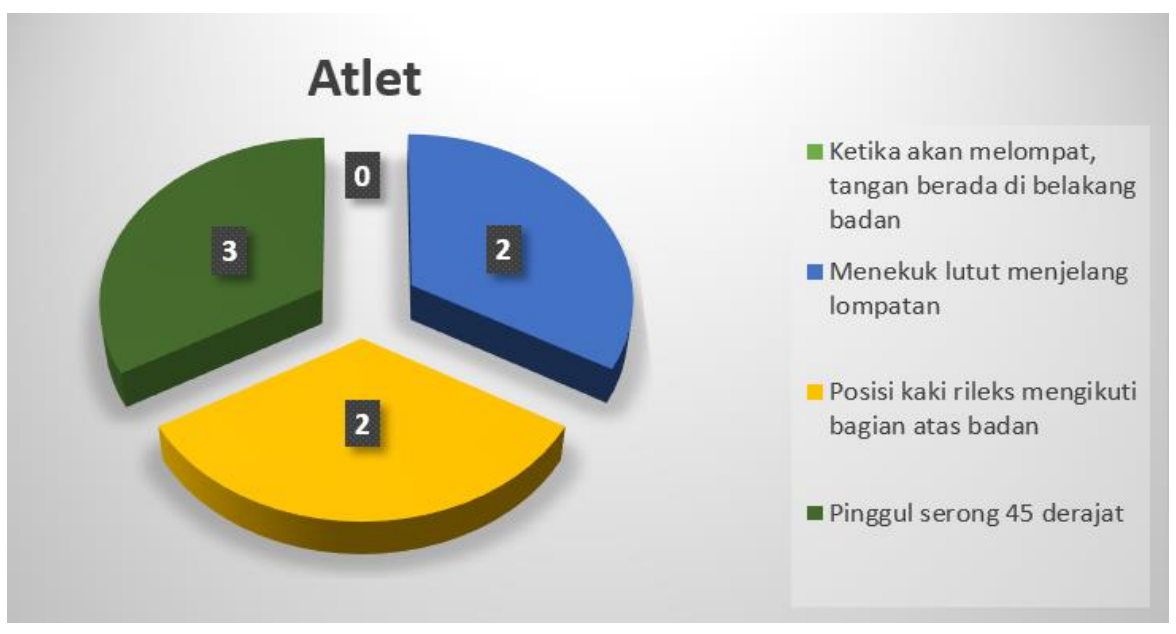

Gambar 2. Diagram Kesalahan Saat Tolakan/Loncatan 
Pada tabel 6, menunjukkan bahwa identifikasi kesalahan teknik smash bola voli klub meteor Pontianak pada tahap memukul dominan terjadi ketika raihan bola tidak berada di depan tangan yang tidak digunakan untuk memukul, yaitu sebanyak 8 atlet.

Tabel 6. Kesalahan Saat Memukul

\begin{tabular}{llll}
\hline No & \multicolumn{1}{c}{ Indikator } & Ya & Tidak \\
\hline 1 & Posisi togok melenting kebelakang & 7 atlet & 4 atlet \\
2 & $\begin{array}{l}\text { Raihan bola berada di depan tangan yang } \\
\text { tidak digunakan untuk memukul }\end{array}$ & 3 atlet & 8 atlet \\
& Posisi siku lurus saat memukul bola & 9 atlet & 2 atlet \\
3 & $\begin{array}{l}\text { Lengan yang digunakan untuk memukul } \\
\text { jatuh lurus ke samping badan mengikuti }\end{array}$ & 6 atlet & 5 atlet \\
& jatuhnya bola & 10 atlet & \\
5 & Kedua kaki menggantung rileks & 10 atlet & 1 atlet \\
6 & Telapak tangan terbuka menghadap bola & 7 atlet & 4 atlet \\
7 & Melecut bola dengan pergelangan tangan & 7 atlet & 4 atlet \\
8 & Perkenaan bola pada raihan tangan & & \\
& tertinggi & &
\end{tabular}

Apabila ditampilkan dalam bentuk diagram, maka hasil identifikasi kesalahan teknik smash bola voli klub meteor Pontianak pada tahap memukul tampak pada gambar sebagai berikut:

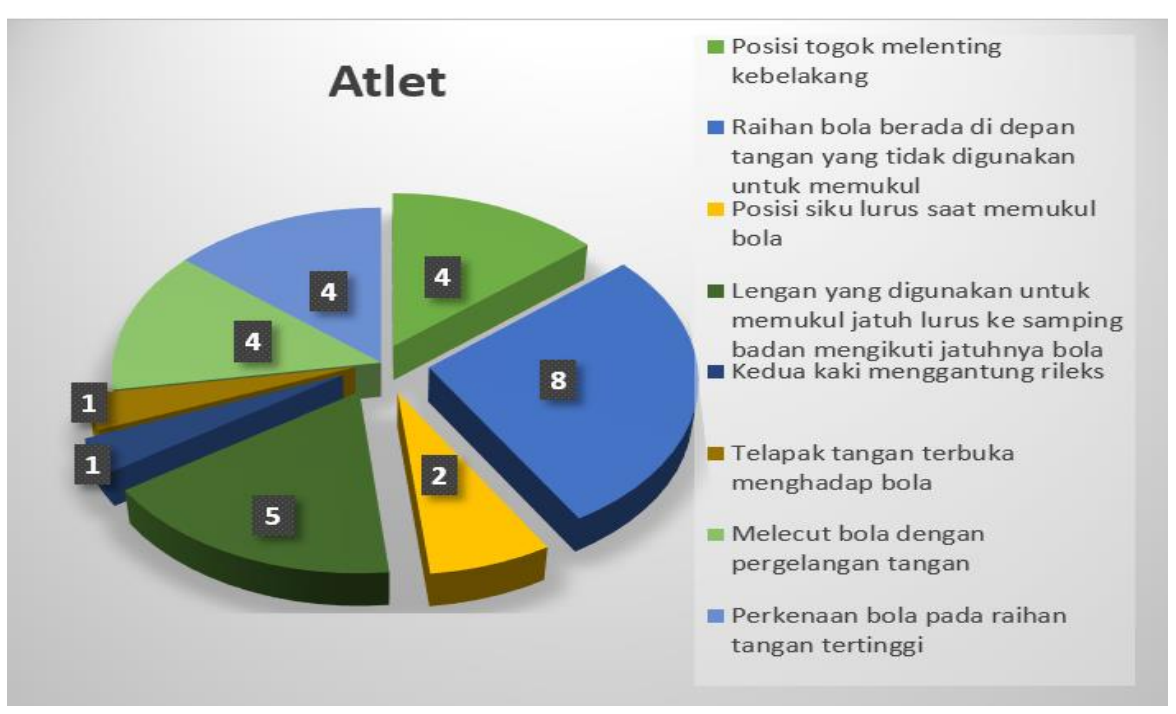

Gambar 3. Diagram Kesalahan Saat Memukul

Pada tabel 7, menunjukkan bahwa identifikasi kesalahan teknik smash bola voli klub meteor Pontianak pada tahap mendarat dominan terjadi ketika atlet mendarat togok tidak membungkuk yaitu sebanyak 5 atlet.

Tabel 7. Kesalahan Saat Memukul

\begin{tabular}{llll}
\hline No & \multicolumn{1}{c}{ Indikator } & Ya & Tidak \\
\hline 1 & Togok sedikit membungkuk & 6 atlet & 5 atlet \\
2 & Mendarat menggunakan dua kaki & 7 atlet & 4 atlet \\
3 & Saat mendarat lutut mengeper & 9 atlet & 2 atlet \\
\hline
\end{tabular}


Apabila ditampilkan dalam bentuk diagram, maka hasil identifikasi kesalahan teknik smash bola voli klub meteor Pontianak pada tahap mendarat tampak pada gambar sebagai berikut:

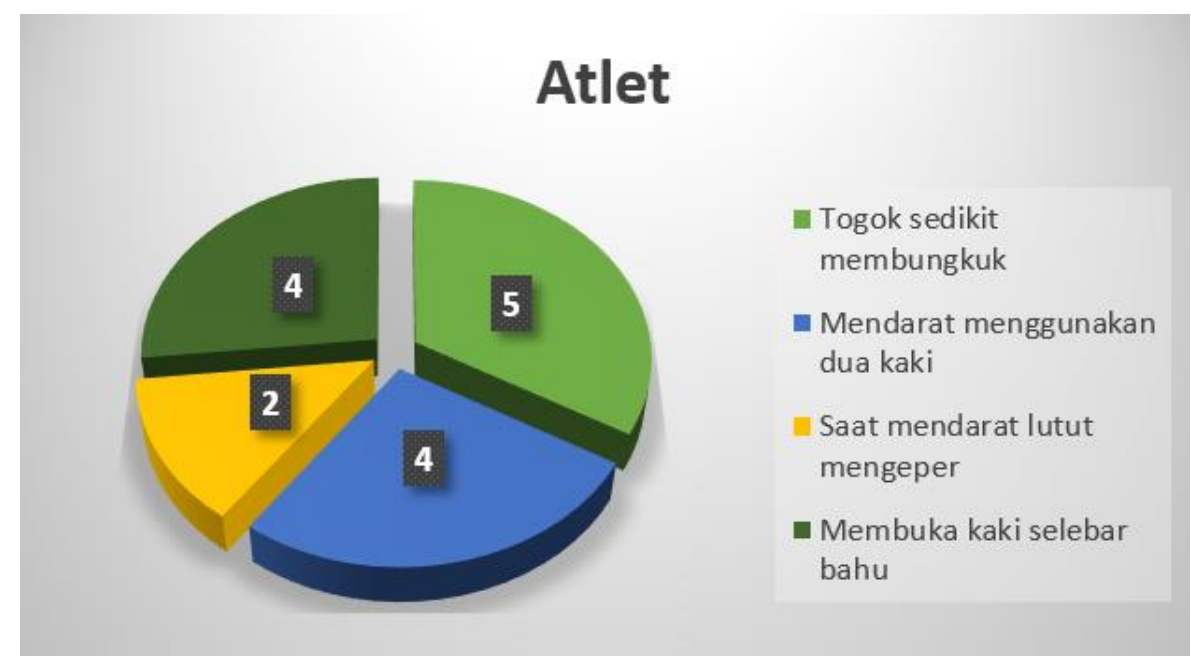

Gambar 4. Diagram Kesalahan Saat Mendarat

\section{Pembahasan}

Berdasarkan hasil penelitian menunjukkan bahwa rata rata atlet yang melakukan kesalahan teknik smash bola voli klub meteor Pontianak termasuk dalam kategori "cukup" sebagaimana presentase Kesalahan Teknik Smah Bola Voli Club Meteor Pontianak dalam 4 tahapan yaitu awalan sebesar $25,75 \%$, tolakan/loncatan sebesar $15,90 \%$, memukul bola sebesar $32,95 \%$, dan mendarat sebesar $34,09 \%$. Berikut hasil pembahasan penelitian secara rinci yang telah di identifikasi oleh peneliti:

\section{Kesalahan saat awalan}

Awalan merupakan bagian penting dalam melakukan smash. Tanpa awalan yang baik maka gerakkan selanjutnya akan terganggu. Dalam penelitian ini terdapat kesalahan yang sangat dominan saat melakukan langkah pertama berupa langkah tidak pendek. Awal mula pemain mengambil sikap siap normal dengan jarak 3-4 meter dari net. Awalan ini sangat berguna untuk memperoleh posisi awal yang baik dalam melakukan lompatan agar tinggi (De Costa dkk, 2011), dengan timming yang pas dan tepat dapat memukul bola secara keras (MacDonald dkk, 2020). Pada saat akan melangkah pertama kedepan, terlebih dulu melakukan langkah-langkah kecil ditempat. Langkah-langkah kecil tersebut dimaksudkan agar tubuh dalam keadaan labil dan seimbang. Keadaan labil dan seimbang diberikan agar tubuh dalam keadaan siap untuk bergerak kedepan melakukan langkah pertama. Keseimbangan merupakan kemampuan untuk mempertahankan kesetimbangan dalam berbagai posisi (Mekayanti, Indrayani, \& Dewi, 2015).

Untuk menjaga dan mempertahankan keseimbangan dan kesetimbangan atlet harus melakukan langkah pertama pendek, Langkah pertama di maksudkan untuk menyesuaikan jauh dan dekatnya bola dengan pemain, agar dapat memperkirakan loncatan sesuai dengan bola yang akan dipukul. Posisi arah hadap tubuh tidak tegak lurus menghadap garis net, melainkan membentuk sudut sehingga tubuh tampak serong kekanan menghadap pengumpan (setter). Dengan demikian yang perlu di perhatikan adalah letak bahu kiri bahu kanan, dalam hal ini letak bahu kiri sharusnya lebih dekat dengan nett daripada bahu sebelah kanan. 
Selanjutnya pada langkah kedua atlet harus sedikit menambah langkah lebih panjang, lalu segera ikuti langkah terakhir panjang dengan tujuan untuk menyeimbangkan percepatan yang telah dibentuk sehingga, tubuh akan memiliki daya ledak power tungkai dalam menghadapi gerak loncatan selanjutnya. Pada posisi ini lutut di tekuk, kedua lenga terjulur dibelakang dan badan dalam keadan relaks. Langkah-langkah kaki dalam melakukan awalan harus tetap di jaga kontinuitasnya.

Ketika langkah awalan terlalu panjang akan merubah langkah selanjutnya, maka kecepatan akan menjadi lebih lambat sehingga terjadi keterlambatan dalam menjangkau bola, hal ini dapat menyebab kerugian bagi atlet. Dengan dilakukannya langkah awalan serta ketepatan memukul yang benar secara berulang-ulang maka dapat melatih respon serta otomatisasi (Erfian, 2013). Kecepatan ditambahkan untuk mempersingkat gerakkan yang sama (Widiastui, 2011). Pendekatan langkah yang biasnya digunakan oleh pemukul yaitu tiga atau empat langkah tergantung preferensi atlet (Sheppard dkk, 2008). Hasil utama dari pendekatan tahap awalan yaitu berlari untuk mencapai kecepatan horizontal maksimum (Proctor, 2014).

Fleksi pada lutut ketika langkah terakhir memberikan gaya tekan pada permukaan yang akan menghasilkan momentum sebelum melakukan loncatan. Semakin banyak gaya yang diterapkan maka perubahan momentum yang terjadi sangat besar, ini dikenal dengan impuls (Blazevich, 2010). Ketika langkah pertama panjang, maka akan mengakibatkan perubahan pada langkah selanjutnya yang akan menyebabkan kerugian pada persiapan meloncat. Untuk mengubah momentum seorang pemain harus memiliki kekuatan penuh power (Blazevich, 2010).

\section{Kesalahan saat tolakan/loncatan}

Faktor antropometri dan biomotor merupakan dua diantara banyak faktor yang dapat menunjang kemampuan lompat bola voli (Setiyawan dkk, 2020). Dalam penelitian ini kesalahan yang dominan terjadi saat tolakan/loncatan yaitu, atlet tidak menyerongkan pinggul sebesar 45 derajat. Lompatan vertikal menjadi peran penting dalam memengaruhi kinerja serangan dan pertahanan (Çankaya dkk, 2018). Pada tahap ini perlu mempertimbangkan beberapa prinsip hukum gerak Newton. Hukum Newton Pertama pemain diharuskan untuk dapat mengatasi kelembaman (Pick, 2013). semua benda pasti memiliki kelembaman, tetapi setiap benda memiliki kelembaman yang berbeda-beda tergantung pada massanya. karena itu pemain bola voli ditekankan untuk memiliki massa tubuh yang rendah untuk memaksimalkan lompatan vertikal sehingga hanya sedikit gaya yang diperlukan (Pick, 2013). Ketinggian yang diperoleh tidak terlepas dari lompatan dan kecepatan sehingga dalam melakukan awalan harus dilakukan secara maksimal (Teri M. Ciapponi, 2005: 33).

Selanjutnya Hukum Newton Kedua yang mepengaruhi percepatan suatu benda sebanding dengan resultan gaya pada benda tersebut dan berbanding terbalik dengan massanya. Keadaan tersebut terjadi pada permain bola voli ketika menapakkan kaki ke tanah akan berdampak pada ketinggian lompatan. Sebaliknya, tanah akan memberikan gaya yang berlawanan untuk memaksa pemain melompat ke udara (Pick, 2013).

Dengan demikian untuk dapat melakukan smash dengan baik, seseorang harus memiliki jangkauan tangan yang relatif tinggi dibantu dengan menyerongkan pinggul pada sudut 45 derajat, maka badan akan mengalami kontraksi bagian pinggang (kelentukan). Kelentukan merupakan ketepatan dalam melakukan gerak scara maksimal (Asnaldi, 2020). Mulai dari bagian togok hingga badan bagian atas untuk membantu gerakkan swing dalam menghasilkan power yang timbul karena adanya kekutan dan kecepatan otot dalam berkontraksi secara maksimal dalam waktu yang secepat mungkin (Jaya \& Rohmat, 2019).

Ketika melakukan rotasi atau gerak berputar yang berpusat pada suatu sumbu putar. Tubuh berputar melalui sumbu gerak persendian pinggul sehingga bola yang dipukul akan maksimal dengan sudut tembak yang lebih luas dan dapat membantu dalam memperbesar momentum saat memukul. Begitupun sebaliknya, ketika pinggul tidak diserongkan maka akan terjadi kerugian sudut tembak pada tubuh sehingga momentum yang dihasilkan akan kecil ataupun sedikit yang akan mengakibatkan pukulan tidak dapat maksimal. Setiap kelompok otot yang berkontraksi pada seluruh tahapan itu penting karena setiap gerakan yang dihasilkan harus dikerahkan dalam satu arah yang sama guna mendapatkan kekuatan maksimum (Sheens, 2014). 


\section{Kesalahan saat memukul}

Kesalahan yang dilakukan saat memukul bola, dominan terjadi ketika raihan bola tidak berada di depan tangan yang tidak digunakan untuk memukul. Sama halnya dengan tahap sebelumnya, lompatan dalam bola voli merupakan gerakan yang sangat cepat, bahu yang tinggi dapat menghasilkan tenaga dan torsi. Torsi dapat di definisikan sebagai kecenderungan gaya untuk memutar suatu benda di sekitar sumbu, titik tumpu, atau poros Blazevich (2010)Ketika pemain melakukan putaran pinggul maka seluruh badan akan mengikuti pergerakkan pinggul sehingga, diperlukannya gerakkan angular berupa putaran pada salah satu sumbu imajeri ataupun sumbu nyata (Ardiyanto \& Widiyanto, 2019). Guna menjangkau bola di depan badan agar ketika memukul pemain dapat memanfaatkan hasil dari momentum. Momentum dapat diperbesar maupun diperkecil dengan cara menambah atau mengurangi massa dan kecepatan (Jannah dkk, 2014).

Untuk memaksimalkan lompatan dalam bola voli diperlukan pengungkit yang panjang. Maka dari itu, dapat dikatakan bahwa semakin panjang lengan, semakin besar peluang untuk meningkatkan jarak antara otot dan sendi, yang menghasilkan jumlah torsi yang lebih besar pada bola (Skoumbros, 2014). Gapaian tangan pada bola merupakan posisi momentum tersebesar sebelum memukul bola, serta gapaian tertinggi berada pada ujung lengan yang tidak digunakan untuk memukul. Sedangkan beberapa atlet melakukan jangkauan bola pada tangan yang akan digunakan untuk memukul sehingga, sangat merugikan sudut angular yang telah dibentuk sebelumnya dan tidak dapat memanfaatkan hasil dari momentum secara maksimal. Pada fase memukul bola kecepatan gapain tangan dan jari-jari berkontribusi sehingga akan menimbulkan gaya maksimal pada perkenaan bola (Blazevich, 2010). Terdapat beberapa aspek yang berpengaruh dalam kecepatan tolakan lompatan yaitu berupa kecepatan ekstensi siku dan bahu, koordinasi beberapa otot tertentu, dan waktu yang tepat (Cerrato dkk, 2016).

\section{Kesalahan saat mendarat}

Kesalahan yang dilakukan saat mendarat, dominan terjadi ketika atlet mendarat togok tidak membungkuk. Tingkat keberhasilan smash tidak hanya terletak pada kemampuan teknik pukulan maupun loncatan saja. Apabila seseorang sudah melakukan pukulan dengan baik tetapi melakukan fase pendaratan yang keliru maka akan menimbulkan kesalahan yang berdampak pada hasil.

Saat mendarat sendi lutut akan menahan beban dengan berat. Ketika mendarat harus menahan berat badan dan kecepatan jatuhnya badan ke lantai (momentum) atau merupakan jumlah kualitas yang ditunjukkan oleh suatu benda bergerak dari hasil perkalian antara massa tubuh dan kecepatan (Taufiq, 2017). Tungkai dan kaki akan mendapat beban tinggi sehingga dengan tumpuan satu kaki ketika mendarat akan mendapatkan beban dua kali lipat. Untuk menjaga keseimbangan dan koordinasi diperlukan kerja sama antara tubuh dengan kedua kaki. Ketika kedua kaki mendarat ke tanah harus diikuti gerakan dorsi flexion dari angkle joint. Kneeflexion, hip flexion dan tubuh dalam keadaan sedikit extension untuk menjaga keseimbangan agar tidak jatuh kedepan.

Mendarat dengan menumpu satu kaki dan dalam keadaan badan miring, dapat mengakibatkan lutut dan tulang belakang mendapat beban yang lebih tinggi. Jika terjadi berkali-kali maka lutut akan mengalami cedera. Ketika gaya yang sama namun berlawanan arahnya yang diberikan oleh tanah ke kaki (GRF) termasuk dalam hukum newton III (Flaviana \& Suryanti, 2016). Untuk meminimalisir cedera pada lutut yang sering terjadi dapat ditanggulangi dengan cara memvariasikan beberapa gerak latihan pada bagian paha, pinggul, dan otot inti secara efisien dengan harapan dapat meredam kekuatan pendaratan (Eerkes, 2012). Seharusnya pada saat mendarat, atlet mendarat dengan kedua kaki tidak kaku dan diikuti oleh badan yang membungkuk karena adanya hentakan ketanah saat mendarat agar terjadi peredaman disana (impact). Perlu dipehatikan saat melakukan pendaratan kaki ke tanah, kaki harus dalam keadaan tentuk dan menekuk karena akan terjadi impact yang besar, maka diperlukan gaya untuk meredam, menghisap, atau memecahkannya. 
Berdasarkan beberapa hasil identifikasi gerak smash dalam empat tahapan, ternyata tahapan memukul bola memiliki kesalahan yang paling besar yaitu dengan presentase $25,42 \%$. Berikut hasil identifikasi pada tahap memukul bola:

Dapat disimpulkan bahwa ketika memukul bola memerlukan kecepatan sudut (angular velocity), dengan menekuk lengan pada persendian maka momen inertia akan semakin kecil sehingga akan memperoleh kecepatan sudut yang maksimal. Saat melayang pada titik tertinggi merupakan momen yang tepat untuk mengeksekusi bola. Ketika bola telah berada di jangkauan lengan pemukul atau posisi depan atas tubuh maka dianjurkan untuk segera memukul secepatnya.

Pada tahap perkenaan juga perlu diperhatikan bahwa lengan yang digunakan untuk memukul harus pada jangkauan tertinggi sehingga posisi siku lurus keatas serta diharapkan jari jari tangan terbuka agar permukaan tangan yang menyentuh bola lebih lebar sehingga smash yang dihasilkan akan lebih bertenaga. Karena pada sat memukul lengan dan badan akan mengalami rotasi. Dengan lengan yang lurus maka gapaian bola akan menjadi lebih panjang sehingga impuls yang dihasilkan lebih besar dan ketika impuls besar dapat membuat mometum tangan yang dihasilka juga besar.

Ketika perkenaan bola benar maka akan menghasilkan top spin yang akan membuat bola turun dengan cepat. Gerakan memukul bola dilakukan dengan langkah- langkah, ayunkan tangan pukul bola dengan membukukkan togok, pukul bola dibagian atas belakang dengan telapak tangan yang terbuka sampai siku lurus, setelah memukul tangan mengikuti arah bola, lalu kesamping (Winarno \& Sugiono, 2011). Sama halnya ketika memukul bola posisi badan membusung sedikit kayang, ada lentingan mengayun tangan serta pengaturan membuang nafas.

\section{KESIMPULAN dan SARAN}

\section{Kesimpulan}

Berdasarkan hasil data penelitian diatas, maka dapat ditarik kesimpulan bahwa identifikasi kesalahan teknik smash bola voli pada Club Meteor sebagai berikut, tahap awalan sebesar 25,39\%, tahap tolakan/loncatan sebesar $25,37 \%$, tahap memukul bola sebesar $25,42 \%$, dan tahap mendarat sebesar $23,82 \%$.

\section{Saran}

Diperlukan upaya untuk meningkatkan latihan pada tahap memukul yang mana memiliki kualitas kesalahan paling besar, Perlu adanya tambahan pola-pola latihan yang mendukung untuk meminimalisir kesalahan dalam melakukan smash, Adanya sosialisasi ataupun coaching clinic agar pelatih dapat mempelajari lebih lanjut tentang bagaimana cara melakukan smash dengan benar, serta diharapkan bagi peneliti selanjutnya agar dapat menganalisis penelitian ini secara lebih spesifik.

\section{DAFTAR PUSTAKA}

Achmad. (2016). Hubungan Antara Power Tungkai, Koordinasi Mata- Tangan, Dan Rasa Percaya Diri Dengan Hasil Keterampilan Open Spike Bola Voli. Jurnal Pendidikan Unsika.

Akbar, W. (2019). Pembinaan Prestasi Cabang Olahraga Tarung Derajat Kabupaten Agam. Jurnal JPDO.

Alfath, K., \& Raharjo, F. F. (2019). Teknik Pengolahan Hasil Asesmen: Teknik Pengolahan Dengan Menggunakan Pendekatan Acuan Norma (PAN) dan Pendekatan Acuan Patokan (PAP). Jurnal Komunikasi Dan Pendidikan Islam.

Asnaldi, A. (2020). Hubungan Kelentukan dan Daya Ledak Otot Lengan Terhadap Ketepatan Smash Bolavoli. Physical Activity Journal. https://doi.org/10.20884/1.paju.2020.1.2.2556 
Çankaya, C., Arabacı, R., Kurt, E., \& Doğan, S. (2018). Examining the effects of the plyometric (jump squat) exercise on vertical jump in female volleyball players. European Journal of Physical Education and Sport Science, 5(2), 115-124. https://doi.org/10.5281/zenodo.1997613

De Costa GCT, Mesquita I, Greco PJ, Ferreira NN, Moraes JC. Layanan hubungan, penerimaan dan serangan dalam bola voli junior putra. Motriz J Phys Pendidikan UNESP. 2011

DP Mekayanti A., NLK Indrayani, dan MK Dewi K. (2015). Optimalisasi kelenturan (flexibility), Keseimbangan (balance), dan kekuatan (strength) tubuh manusia secara instan dengan menggunakan "Secret Method". Jurnal Virgin 1 (1)-40-49.

Education, P. (2011). Trajković , $N$. et al .: Positional differences in body composition and jumping ... POSITIONAL DIFFERENCES IN BODY COMPOSITION AND JUMPING PERFORMANCE AMONG YOUTH ELITE VOLLEYBALL PLAYERS Original scientific paper Abstract Trajković , $N$. et al .: Positiona. 5, 62-66.

Eerkes, K. Cedera Bola Voli. Curr. Olahraga Med. Rep. 2012 , 11, 251-256.

Erfian Dedy, Setyawan. 2013. Skripsi: Pengaruh Latihan Memukul Bola Gantung TerhadapKetepatan Smash Peserta Ekstrakulikuler Bolavoli di SMK Tunas Cawan Klaten. Yogyakarta: Universitas Negeri Yogyakarta.

Forthomme, B., Croisier, J. L., Ciccarone, G., Crielaard, J. M., \& Cloes, M. (2005). Factors correlated with volleyball spike velocity. American Journal of Sports Medicine, 33(10), 1513-1519. https://doi.org/10.1177/0363546505274935

Hidayat, S., Riyanto, ., \& Rosman, D. B. (2018). Pengaruh Metode Bermain Terhadap Peningkatan Passing Bawah Dalam Permainan Bola Voli Siswa Ekstrakurikuler SMK Negeri 1 Subang. Biormatika, Jurnal Ilmiah FIKP Universitas Subang.

Hughes, A. (2014). What are the biomechanics underpinning a powerful and fast volleyball spike? Biomechanical Principles of a Volleyball Spike. Retrieved from http://amyhughes027.blogspot.com.au

IRWANTO, E. (2013). PENGEMBANGAN MODEL VARIASI SERANGAN PERMAINAN BOLAVOLI PADA EKSTRAKURIKULER BOLAVOLI PUTRA DI SMA PGRI PURWOHARJO BANYUWANGI. Journal of Chemical Information and Modeling.

Iskandar, \& Yulianingsih. (2015). Peningkatan Keterampilan Passing Atas dalam Permainan Bola Voli Melalui Metode Bermain Siswa Kelas VIII SMP Negeri 3 Sungai Ambawang. Jurnal Pendidikan Olahraga.

Jannah, F. Z., Perdana, A., Nurhasanah, S., Suryano, N., Jutalo, Y. H., \& Budi, S. (2012). Analisis Biomekanika Dalam Gerakan Dasar Anggar. In Prosiding Seminar Nasional Fisika (E-Journal).

Jaya, M. K., \& Rohmat, D. (2019). Perbandingan Latihan Plyometric Jump to Box dan Knee Tuck Jump terhadap Peningkatan Muscle Power pada Atlet Dayung Rowing. Jurnal Kepelatihan Olahraga. https://doi.org/10.17509/jko-upi.v11i1.16828

Kresnapati, P. (2020). Perbedaan latihan passing berpasangan dengan perubahan tinggi net berat bola terhadap kemampuan passing bawah. Edu Sportivo: Indonesian Journal of Physical Education. https://doi.org/10.25299/es:ijope.2020.vol1(1).5116 
Kurniawan, F. (2015). ANALISIS SECARA BIOMEKANIKA TERHADAP KEKERAPAN KESALAHAN PADA TEKNIK GERAK SERANG DALAM PERTANDINGAN ANGGAR (KAJIAN SPESIFIKASI SENJATA FLORET). Jurnal Olahraga Prestasi. https://doi.org/10.21831/jorpres.v11i1.10261

Laporta, L., Nikolaidis, P., Thomas, L., \& Afonso, J. (2015). Attack Coverage in High-Level Men's Volleyball: Organization on the Edge of Chaos? Journal of Human Kinetics, 47(1), 249-257. https://doi.org/10.1515/hukin-2015-0080

Lenberg, K. (2006). Volleyball skills \& drills. Champaign, IL: Human Kinetics.

MacDonald K, Palacios-Derflingher L, Kenny S, Emery C, Meeuwisse WH. Lutut Pelompat: A Evaluasi Calon Faktor Risiko di Pemain Bola Voli Menggunakan Ukuran Baru Cedera. Clin J Sport Med. 2020

\section{MENINGKATKAN KETERAMPILAN BOLAVOLI MAHASISWA PENJAS DENGAN METODE LATIHAN. (2015). Journal of Physical Education Health and Sport. https://doi.org/10.15294/jpehs.v2i1.3936}

Muttaqin, I., Winarno, M. E., \& Kurniawan, A. (2016). Pengembangan Model Latihan Smash Bolavoli Pada Kegiatan Ekstrakurikuler di SMPN 12 Malang. Journal of Chemical Information and Modeling.

Nurfalah, S., Hanif, A. S., \& Satyakarnawijaya, Y. (2019). MODEL LATIHAN SMASH DALAM PERMAINAN BOLA VOLI UNTUK PEMULA. Jurnal Pendidikan Olahraga. https://doi.org/10.31571/jpo.v8i1.1216

Prinsip-Prinsip Biomekanika Kualitatif: Upaya Menjembatani Teori dan Aplikasi dalam Sport Science. (2019). Media Ilmu Keolahragaan Indonesia. https://doi.org/10.15294/miki.v9i2.17757

Proctor, J. (2014). How can an understanding of the biomechanics behind the volleyball spike be used to better performance outcomes? Biomechanics Blog. Retrieved from http://joshproctor10.blogspot.com.au

Purnomo, E. (2015). Hambatan Perguruan Pencak Silat Tapak Suci Putera Muhammadiyah Provinsi Kalimantan Barat DalamMeraih Prestasi. Jurnal IImiah Mitra Swara Ganesha.

Samiyah. (2013). HUBUNGAN ANTARA KECEPATAN LARI DAN KEKUATAN OTOT TUNGKAI DENGAN HASIL LOMPAT JAUH PADA SISWA PUTRA KELAS ATAS SD NEGERI 3 TAMBAKMULYO KECAMATAN PURING KABUPATEN KEBUMEN TAHUN PELAJARAN 2012/2013. In Journal of Petrology.

Setiyawan, A. A., Kristiyanto, A., \& Purnama, S. K. (2021). Factors Determining the Ability of Jump Volleyball Providing. Health, Sport, Rehabilitation, 7(1), 54-65. https://doi.org/10.34142/hsr.2021.07.01.05

Seyfadin, D. L., \& Mahyadin, T. G. (2016). Effect Of Plyometric Training On Vertical Jump Performance And Neuromuscular Adaptation In Volleyball Player. Halabja University Journal, 1(2), 495-506. https://doi.org/10.32410/huj.10050

Sheens, C. (2014). What biomechanical principals are determiners to creating a Volleyball spike that has increased power and strength with great accuracy? Biomechanics Blog: Volleyball Spike. Retrieved from http://hlpeclaudiasheens.blogspot.com.au/ 
Sheppard, J. M., Cronin, J. B., Gabbett, T. J., Mcguigan, M. R., Etxebarria, N., \& Newton, R. U. (2008). Relative importance of strength, power, and anthropometric measures to jump performance of elite volleyball players. Journal of Strength and Conditioning Research, 22(3). https://doi.org/10.1519/JSC.0b013e31816a8440

Skoumbros, A. (2014). What are the biomechanics underpinning a powerful and fast volleyball spike? Biomechanics Blog: The Volleyball Spike Retrieved from http://antheasbiomechanicsblog.blogspot.com.au/

Srianto, W. (2018). Pengembangan Model Latihan Teknik Smash Dalam Olahraga Bola Voli. In Trihayu: Jurnal pendidikan Ke-SD-an.

Sudiarto, F. K. (2013). Hubungan Daya Ledak Tungkai, Kekuatan Lengan dan Kelentukan Pergelangan Tangan dengan Hasil Back Attack Bola Voli Putra Bahurekso Tahun 2013. Skripsi, Pendidikan Kepelatihan Olahraga, Fakultas Ilmu Keolahragaan, Universitas Negeri Semarang.

Suhairi, M., Asmawi, M., Tangkudung, J., Hanif, A. S., \& Dlis, F. (2019). Development of smash skills training model volleyball based on interactive multimedia. International Journal of Recent Technology and Engineering, 8(2), 2774-2781. https://doi.org/10.35940/ijrte.B2619.078219

Taufiq. (2017). Eksperimen Berpikir ( Thought Experiments ); Beberapa Kasus dalam Hukum Newton. Prosiding Seminar Nasional Pendidikan IPA 2017.

Valadés Cerrato, D., Palao, J. M., Aúnsolo, Á., \& Ureña, A. (2016). Correlation between ball speed of the spike and the strength condition of a professional women's volleyball team during the season. Kinesiology, 48(1), 87-94. https://doi.org/10.26582/k.48.1.7

Widiastuti. 2011. Tes dan Pengukuran Olahraga, Jakarta : PT. Bumi Timur Jaya.

Yani, A., Subekti, R. G., \& Suryadi, S. (2020). PENGARUH LATIHAN PLYOMETRIC (SHOOTING) TERHADAP HASIL TINGGI LONCATAN DALAM EKSTRAKURIKULER BOLA VOLI. Jurnal Pendidikan Olahraga. https://doi.org/10.31571/jpo.v9i1.1705

Zainal\&Taufiq. (2014). Penerapan Model Pembelajaran Stad (Student Teams-Achievement Division) Terhadap Hasil Belajar Ketepatan Service Bawah Bolavoli. Jurnal Pendidikan Jasmani.

Teri M. Ciapponi. (2005). The Volleyball approach: an exploration of balance, California State University, Chico, CA, USA. Volleyball Technical Journal, 8(2), 33-41. Diambil 10 Januari 2012. http://www.csuchico.edu/ jhudson/pdf/ciappo96.pdf 